\title{
Study on the Microstructure and Mechanical Properties of 20 Steel Strain Aging
}

\author{
Mengli Li ${ }^{1, a}$, Weiqiang Wang ${ }^{2, b}$ \\ ${ }^{1}$ school of mechanical and automotive engineering, Qilu university of technology , Jinan, China \\ ${ }^{2}$ school of mechanical engineering dept. name of organization, Shandong university, Jinan, China \\ amiling001@163.com, bwqwang@sdu.edu.cn
}

Keywords: 20 steel, strain aging, microstructure, mechanical properties

\begin{abstract}
The strain aging process in the prefabrication process of 20 steel high-pressure pipe was simulated. The microstructure, hardness and impact absorption energy of the 20 steel pipes in the process were studied, and the mechanism was explained. The study shows that normalizing before prefabricated and stress relief annealing after prefabricated can be better to ensure the performance of the elbow.
\end{abstract}

\section{Introduction}

High-pressure pipes are an important part of large-scale industrial installations in industries such as ammonia synthesis, oil hydrocracking and power generation. 20 Steel is one of the most widely used steel. In recent years, a number of failure cases even explosion about high pressure pipe caused by strain aging have occurred. According to the survey, the same risk factors as the accident pipeline exists in a large number of high pressure pipes in the fertilizer, energy and power enterprises. Therefore, it is very important to optimize the production process and improve the safety of the highpressure pipes by studying the regular relationship between the influencing factors and the microstructure and mechanical properties.

Some material organization and performance changes were qualitative and quantitative tested, and a number of trends strain aging factors were summed up. A. Beukel presented theory of the effect of dynamic strain aging on mechanical properties[1]. T. Peng studied the brittle law of the X100 pipeline steel in the strain aging by using micro-analysis methods and mechanical properties test[2]. M. Li studied avoiding and eliminating strain aging embrittlement by heat treatment methods commonly used in engineering [3]. N. Han et al.[4] and M. Chemingui et al.[5] studied the effect of stretching and aging on the microstructure of 7050 aluminum alloy and Al-Zn-Mg alloy by optical microscopy, scanning electron microscopy and transmission electron microscopy. A. Vasilyev et al.[6] revealed that the strain aging behavior of ultra-low carbon bake hardened steels in industrial production was the pinning of the gap atoms to dislocations.

S. Serajzadeh et al.[7] argued that the static strain aging after hot rolling leaded to an increase in material yield strength and tensile strength. M. Chemingui et al.[5] tested the mechanical properties of Al-Zn-Mg alloy at $70^{\circ} \mathrm{C}$ and $135^{\circ} \mathrm{C}$ in two aging steps with hardness and tensile tests. M. Shahriary et al.[8] studied the effect of dynamic strain aging on room temperature mechanical properties of high martensite dual phase (HMDP) steel, and S. Luo et al. [9] studied the effect of dynamic strain aging on the microstructure and mechanical properties of a reactor pressure vessel steel. S Lou et al.[10] studied the elevated temperature mechanical properties and dynamic strain aging in pressure vessel quality steel plate.

The main contents of this paper are the evolution of microstructures and mechanical properties of 20 steel under various strain aging factors. 


\section{Test design}

\subsection{Test material}

Test material is $\varnothing 273 \times 40$ specifications of 20 steel pipes from a prefabricated factory without service. Material composition in Table 1 meets the relevant standards at home and abroad. The material is recorded as N85.

TABLE 1. THE CHEMICAL COMPOSITION OF 20 STEEL (W\%)

\begin{tabular}{|c|c|c|c|c|c|}
\hline Number & $\boldsymbol{W}_{\mathbf{C}}$ & $\boldsymbol{W}_{\mathbf{S i}}$ & $\boldsymbol{W}_{\mathbf{M n}}$ & $\boldsymbol{W}_{\mathbf{P}}$ & $\boldsymbol{W}_{\mathbf{S}}$ \\
\hline N85 & 0.220 & 0.270 & 0.535 & 0.018 & 0.0039 \\
\hline GB6479 & $0.17-0.24$ & $0.17-0.37$ & $0.35-0.65$ & $\leqq 0.030$ & $\leqq 0.030$ \\
\hline GB9948 & $0.17-0.23$ & $0.17-0.37$ & $0.35-0.65$ & $\leqq 0.030$ & $\leqq 0.020$ \\
\hline GB5310G & $0.17-0.23$ & $0.17-0.37$ & $0.35-0.65$ & $\leqq 0.025$ & $\leqq 0.015$ \\
\hline AISI1020 & $0.18-0.23$ & & $0.30-0.60$ & $\leqq 0.04$ & $\leqq 0.05$ \\
\hline
\end{tabular}

\subsection{Heat treatment method and process}

Industrial steel pipe treatment process was simulated. Prefabricated process was simulated with different strain and aging, normalizing before prefabricated and stress relief annealing after prefabricated.

Plastic deformation values are respectively $0 \%, 5 \%, 7 \%, 8 \%$ and $10 \%$ from small to large, along the steel pipe axis direction. The maximum deformation of the test is $10 \%$. Heat treatment is shown in Table 2.

TABLE 2. HEAT TREATMENT

\begin{tabular}{|c|c|c|c|}
\hline Heat treatment & $\begin{array}{c}\text { Heating } \\
\text { temperature }\end{array}$ & $\begin{array}{c}\text { Holding } \\
\text { time }\end{array}$ & Cooling method \\
\hline Normalizing & $910^{\circ} \mathrm{C} \pm 10^{\circ} \mathrm{C}$ & $3 \mathrm{~mm} / \mathrm{min}$ & Air cooling \\
\hline Aging & $250^{\circ} \mathrm{C}$ & 1 hour & Air cooling \\
\hline $\begin{array}{c}\text { Stress relief annealing with high } \\
\text { temperature }\end{array}$ & $635^{\circ} \mathrm{C} \pm 10^{\circ} \mathrm{C}$ & $3 \mathrm{~mm} / \mathrm{min}$ & $\begin{array}{c}\text { Furnace cooling to } 350{ }^{\circ} \mathrm{C} \\
\text { then air cooling }\end{array}$ \\
\hline $\begin{array}{c}\text { Stress relief annealing with low } \\
\text { temperature }\end{array}$ & $590^{\circ} \mathrm{C} \pm 10^{\circ} \mathrm{C}$ & $3 \mathrm{~mm} / \mathrm{min}$ & $\begin{array}{c}\text { Furnace cooling to } 350{ }^{\circ} \mathrm{C} \\
\text { then air cooling }\end{array}$ \\
\hline
\end{tabular}

\section{Test results and analysis}

\subsection{Microstructure}

1) Normalizing microstructure

Metallographic structure of normalizing N85 shown in Fig.1, the ferrite-pearlite is homogeneous. SEM structure shown in Fig.2, cementite layer is thin, and the gap is small.

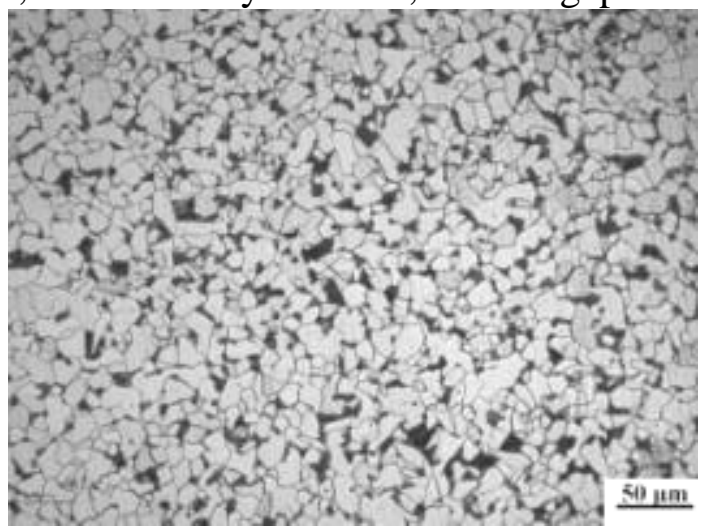

Figure 1. Normalizing metallographic of N85 


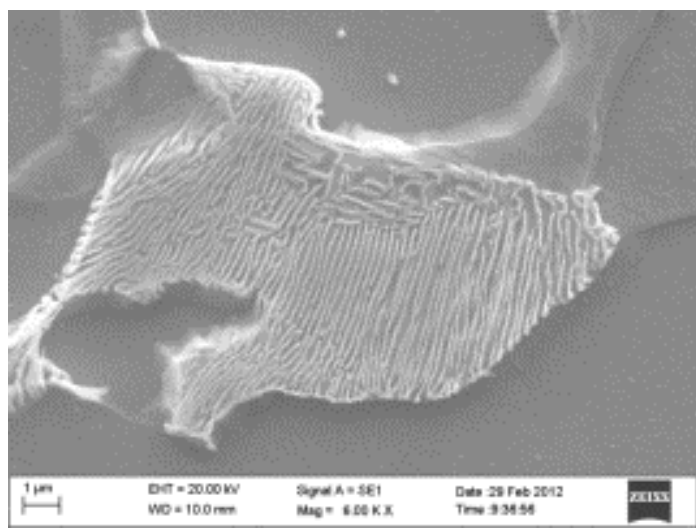

Figure 2. The pearlite of normalizing N85

2) the microstructure with normalizing and plastic deformation

They have no significant change which are in the OM structure and the SEM structure of N85 with $7 \%$ plastic deformation after normalizing and SEM microstructure with $10 \%$ strain aging after normalizing compared with the pearlite in the heat treatment.

3) The pearlite with normalizing and different strain aging and stress relief annealing

a) The pearlite with stress relief annealing at different temperatures

The microstructures of N85 with normalizing and $10 \%$ strain aging and $590^{\circ} \mathrm{C}$ and $635^{\circ} \mathrm{C}$ stress relief annealing respectively are shown in Fig.3 and Fig.4. The sheet cementite converts into pellets partly and almost all after $590^{\circ} \mathrm{C}$ and $635^{\circ} \mathrm{C}$ stress relief annealing respectively. The pearlites in two processes both remain the original shape. The cementite does not diffuse into the eutectoid ferrite.

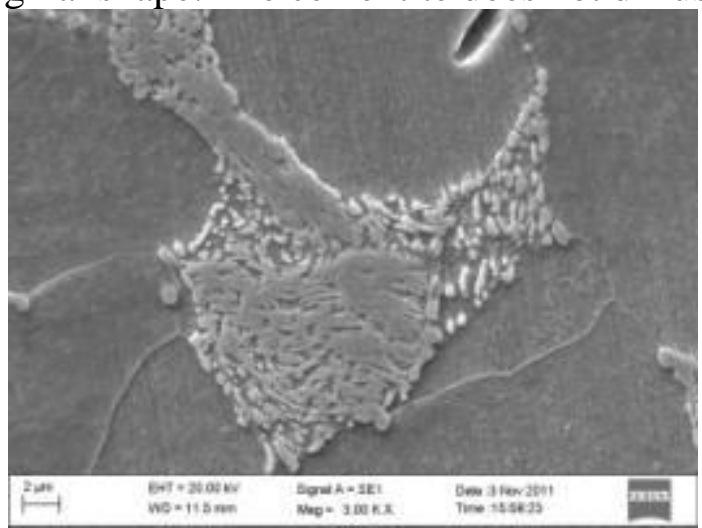

Figure 3 . The $590^{\circ} \mathrm{C}$ stress relief annealing microstructure with $10 \%$ strain aging after normalizing of N85 with SEM

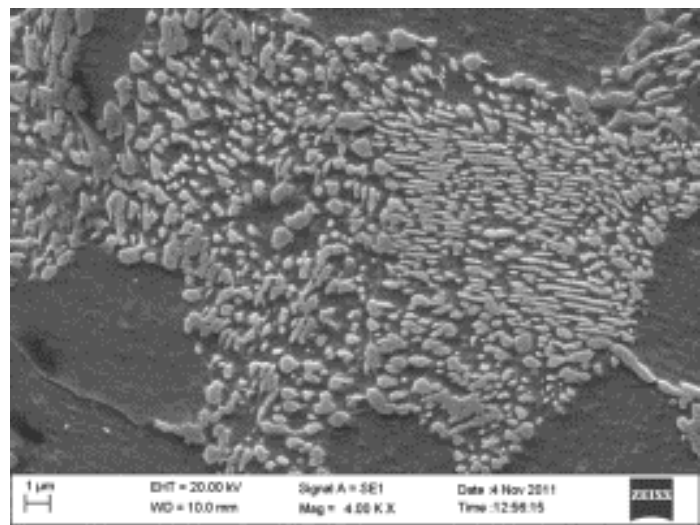

Figure 4. The $635^{\circ} \mathrm{C}$ stress relief annealing microstructure with $10 \%$ strain aging after normalizing of N85 with SEM

The pearlite is a metastable structure. When annealing can reduce the driving force of the interface, the lamellar cementite is spontaneously transformed into granular form due to its large surface area and high interfacial energy. For the 20 steel with the same amount of cementite, the 
strength and hardness of granular pearlite is lower than that of lamellar pearlite, but the plasticity is better, the fracture strength and fatigue resistance are higher, and the ductile and brittle transition temperature is lower.

b) The pearlite with normalizing and different strain aging and stress relief annealing

The SEM structures of N85 with normalizing and 5\%, 8\% and 10\% strain aging separately and stress annealing are shown in Fig.5, Fig.6 and Fig.4. There is a phenomenon of granulation phenomenon of cementite in pearlite, and the degree of granulation increases with plastic deformation.

\subsection{Hardness evolution}

4) Hardness evolution of heat treatment and 10\% strain aging and stress relief annealing

The hardness of 20 steel with non-heat treatment cannot be higher than 156HBS in the 《GB/T699-2015 high-quality carbon structural steel》. The hardness of N85 with as-received or normalizing, $10 \%$ plastic deformation, aging, stress relief annealing in turn are shown in Fig.7. The hardness of as-received N85 and normalized N85 meet with the requirements of GB/T699. The hardness of N85 with 10\% plastic deformation after heat treatment increases a lot, more than 156HBS. The hardness after aging is further increased relative to plastic deformation, which is much higher than that of 156HBS. Then after stress relief annealing, the hardness decreases significantly, but still slightly higher than 156HBS.

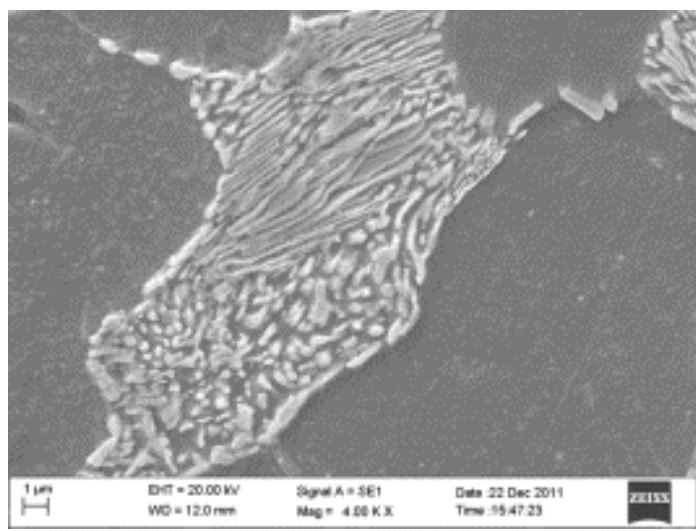

Figure 5. The stress relief annealing microstructure with 5\% strain aging after normalizing of N85

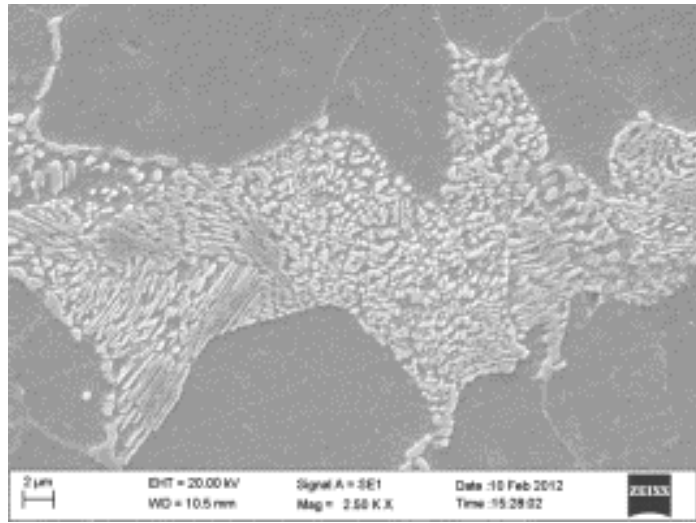

Figure 6. The stress relief annealing microstructure with 8\% strain aging after normalizing of N85 


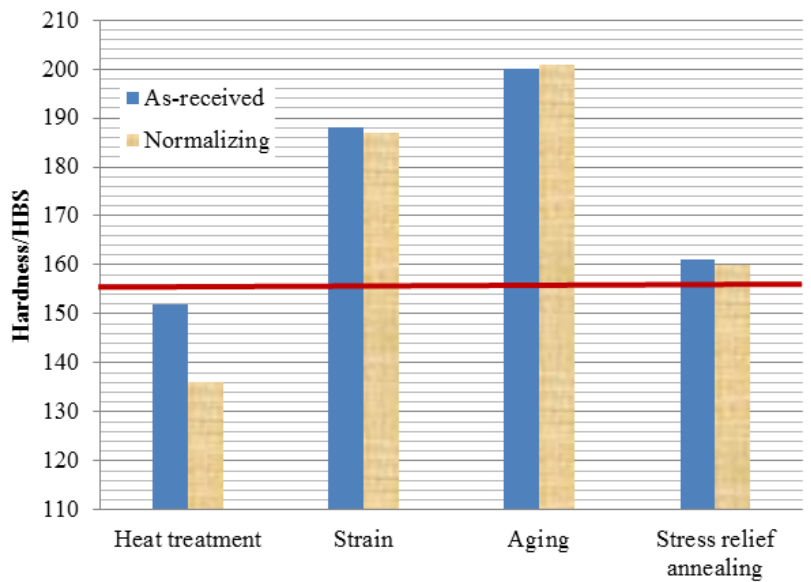

Figure 7. The N85 hardness changes at the process of at different heat treatment, $10 \%$ strain aging and stress relief annealing

5) The hardness with normalizing and different strain aging and stress relief annealing

The hardness of N85 with normalizing and $5 \%$ or $8 \%$ or $10 \%$ strain aging and stress relief annealing are shown in Fig.8. The hardness increases with increasing strain. The hardness with various strain after aging is higher than 156HBS. after stress relief annealing, the hardness with $5 \%$ strain is less than $156 \mathrm{HBS}$, both $8 \%$ and $10 \%$ are still slightly higher than $156 \mathrm{HBS}$.

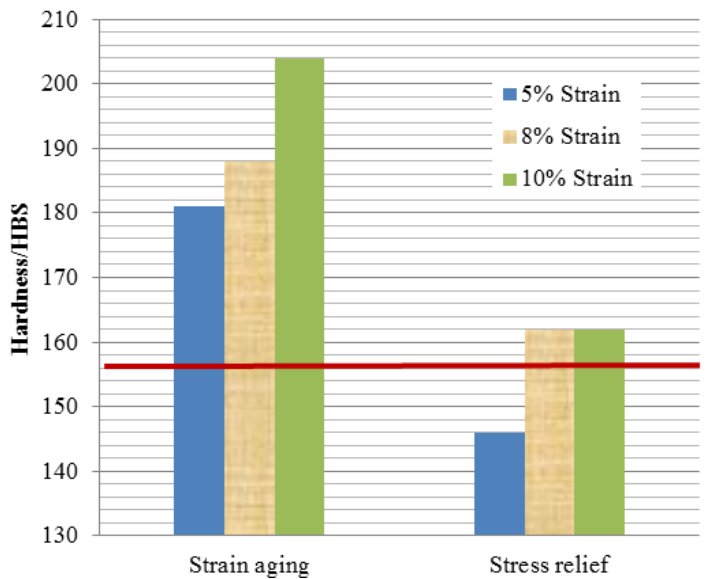

Figure 8. The hardness diagram of different stain aging and stress relief annealing

\section{B. Impact absorption energy}

《GB9948-2013 Seamless steel pipe for oil cracking》 provides that the impact absorption energy of 20 steel is not less than 35J, while 《GB5310-2008 high pressure boiler seamless steel pipe》 provides the impact absorption energy is not less than 40J. The higher 40J is used as the criteria for impact absorption energy.

\section{1) Strain aging}

The Charpy V-notch impact absorption energy at room temperature $5{ }^{\circ} \mathrm{C}$ of $\mathrm{N} 85$ with different heat treatment and strain aging is shown in Fig.9. The impact absorption energy of as-received N85 is less than 40J. It is more than 100 after normalizing, which is greatly improved after normalizing. The impact absorption energy drops sharply to less than 20J after strain aging at two kinds of state. $10 \%$ strain and aging at $250^{\circ} \mathrm{C}$ for $1 \mathrm{~h}$ make 20 steel completely brittle. 


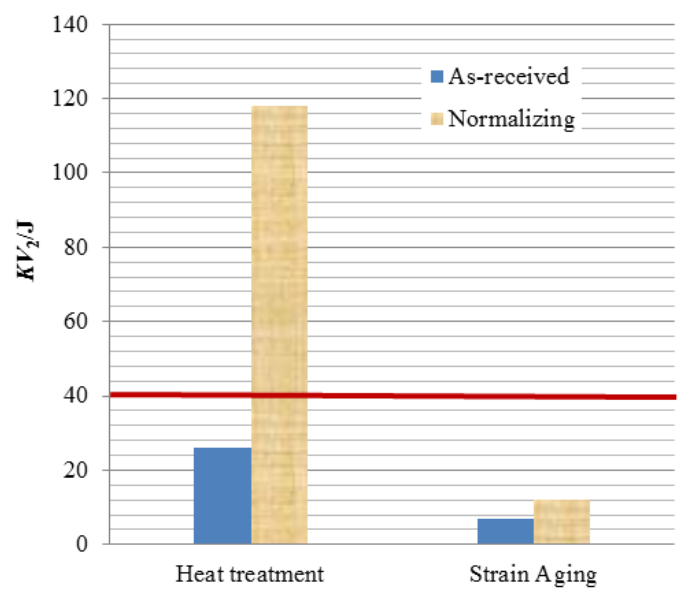

Figure 9. The impact absorbed energy of N85 with heat treatment and strain aging at $5{ }^{\circ} \mathrm{C}$

2) Stress relief annealing

Impact absorption energy of N85 with different treatment and 10\% strain aging and stress relief annealing at room temperature $15^{\circ} \mathrm{C}$ is shown in Fig.10. With stress relief annealing after $10 \%$ strain aging, the impact absorption energy decreases to meet the standard requirements.

The difference between the impact absorption energy of as-received $\mathrm{N} 85$ at $15^{\circ} \mathrm{C}$ and $5{ }^{\circ} \mathrm{C}$ is very large. the impact absorption energy of $15^{\circ} \mathrm{C}$ is higher than $40 \mathrm{~J}$, and it is lower than $40 \mathrm{~J}$ at $5^{\circ} \mathrm{C}$, which indicates that the as-received N85 occur ductile-brittle transition at room temperature. The Normalizing 20 steel reaches the standard requirement at both temperatures.

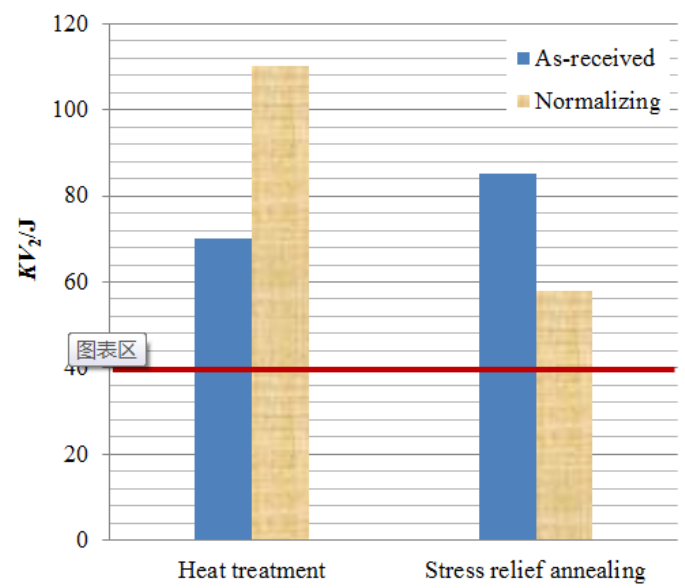

Figure 10. The impact absorbed energy of N85 with heat treatment and 10\% strain aging combined with stress relief annealing at $15^{\circ} \mathrm{C}$

3) The impact absorption energy with normalizing and different strain aging and stress annealing

The impact absorption energy of N85 with normalizing, different strain aging and stress relief annealing in turn is shown in Fig.11. 


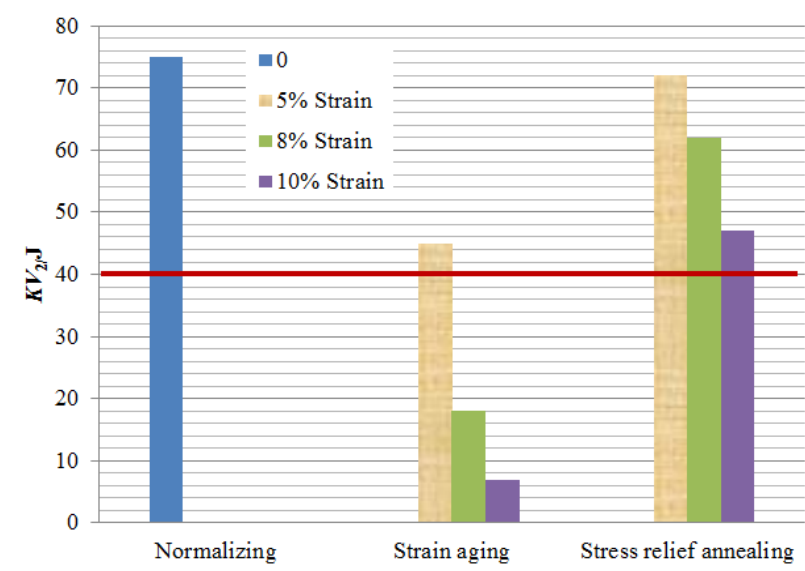

Figure 11. The impact absorption energy of different plastic deformation and heat treatments

The impact absorption energy with normalizing is higher. the impact absorption energy after the strain aging is much lower than that with normalizing. The greater the plastic deformation, the greater the impact absorption can be reduced. the impact absorption energy with Stress relief annealing increase to meet the standard requirements. The smaller the plastic deformation, the better the recovery is.

\section{Conclusions}

The microstructure of 20 steel with normalizing is fine and uniform. no significant changes is observed after strain after aging. to stress annealing after the trend of pelleting. There is a tendency to pelleting after stress relief annealing due to stretching.

Both the impact absorption energy and hardness are in the standard range with normalizing, which are lower than the standard requirements after strain aging. mechanical properties increase to meet the standard requirements after stress relief annealing.

According to the experimental results, it is suggested that the normalizing and stress relief annealing are carried out before and after 20 steel pipe is prefabricated separately.

\section{References}

[1] A. Beukel, Theory of The Effect of Dynamic Strain Aging on Mechanical Properties.Physica Status Solidi. , 1975 , 30 (1) :197-206.

[2] T. Peng, S. Cheng, L. Ji, X. Zhang, H. Gao, Brittle of X100 Pipeline Steel in Strain Aging. Hot processing technology, 2013 , 42 (20): 179-181

[3] M. Li, W. Wang, A. Li, H. Cui, Z. Chen, Experimental Study on the Effect of Heat Treatment on Avoiding and Eliminating Strain Aging of 20 Steel Thick Wall High Pressure Tubes. Materials Engineering , 2011 (1) :57-63

[4] N. Han, X. Zhang, S. Liu, B. Ke, X. Xin. Effects of pre-stretching and ageing on the strength and fracture toughness of aluminum alloy 7050 [J]. Materials Science and Engineering: A, 2011, 528 : 3714-3721.

[5] Chemingui, M. Khitouni, K. Jozwiak, G. Mesmacque, A. Kolsi, Characterization of the mechanical properties changes in an Al-Zn-Mg alloy after a two-step ageing treatment at $70^{\circ} \mathrm{C}$ and $135^{\circ} \mathrm{C}$ [J]. Materials \& Design, 2010, 31 : 3134-3139.

[6] A. Vasilyev, H. Lee, N. Kuzmin, L. Nikolay, Nature of strain aging stages in bake hardening steel for automotive application [J]. Materials Science and Engineering: A, 2008, 485 : 282-289.

[7] S. Serajzadeh, J. Akhgar, A study on strain ageing during and after warm rolling of carbon 
steel [J]. Materials Letters, 2008, 62 : 946-948.

[8] M.Shahriary , B. Koohbor , K. Ahadi, A. Ekrami , M. Khakian-Qom, The effect of dynamic strain aging on room temperature mechanical properties of high martensite dual phase (HMDP) steel.Materials Science \& Engineering A , 2012 , 550 (6) :325-332

[9] S. Luo, S. Wu, Effect of dynamic strain aging on the microstructure and mechanical properties of a reactor pressure vessel steel. Materials Science \& Engineering A , 2014 , 596 (4) :25-31.

[10] S. Lou, D. Northwood, Elevated Temperature Mechanical Properties and Dynamic Strain Aging in Pressure Vessel Quality Steel Plate. Canadian Metallurgical Quarterly , 2013 , 31 (3) :225229. 